\title{
PENGUJIAN TABUNG KOLIMATOR PESAWAT SINAR-X MERK TOSHIBA TYPE E2739 DI LABORATORIUM RADIOLOGI UNIVERSITAS BAITURRAHMAH PADANG
}

\author{
Dila Nelvo Dasril \\ Program Studi DIII Radiologi Universitas Baiturrahmah, \\ Jalan Raya Bypass KM 15 Aie Pacah Padang \\ *Korespondensi ke: dilanelvodasril@atro.unbrah.ac.id
}

( Diterima:22 April 2019; Direvisi: 08 Juli 2019; Diterbitkan: 01 September 2019)

\begin{abstract}
ABSTRAK
Telah dilakukan pengujian tabung kolimasi pesawat sinar-X konvensional. Tujuan dari penelitian ini adalah untuk mengetahui iluminensi lampu kolimator dan kesamaan berkas cahaya kolimasi pada pesawat tersebut. Penelitian dilakukan di laboratorium radiologi jurusan DIII Radiologi Universitas Baiturrahmah. Jenis penelitian yang digunakan yaitu penelitian kuantitatif experimental dengan langsung meneliti ke lapangan. Alat-alat yang digunakan dalam penelitian ini adalah Lux Meter, Collimator Alignment Test Tool dan Beam Alignment Test Tool, dengan menggunakan Focus Film Distace (FFD) $100 \mathrm{~cm}$. Hasil yang diperoleh dari penelitian untuk uji iluminensi lampu kolimator adalah 124,75 lux masih berada dalam batas toleransi yaitu lebih dari 100 lux pada jarak 1 meter dan untuk hasil uji kesamaan berkas cahaya kolimasi adalah berupa penyimpangan sebesar $\Delta X$ sebesar $1 \mathrm{~cm}$ dan $\Delta Y$ sebesar $1,3 \mathrm{~cm}$ dan deviasi sebesar 1,5 derajat. Nilai ini masih berada dalam rentang toleransi pengukuran NCRP (National Council on Radiation Protection and Measurements) yaitu $\Delta \mathrm{X}$ dan $\Delta \mathrm{Y} \leq 2 \%$ FFD dan deviasi $\leq 3^{0}$. Dengan demikian pengujian terhadap tabung kolimasi pesawat sinar-X konvensional ini telah sesuai standar KEPMENKES No.1250/MENKES/SK/XII/2009 tentang Pedoman Kendali Mutu (Quality Assurance) Peralatan Radiodiagnostik.

Kata kunci: pesawat sinar-X Toshiba type E2739, uji iluminensi, uji kesamaan berkas kolimasi.
\end{abstract}

\begin{abstract}
The measurement has been carried out the tube collimation of a conventional X-Ray. The purpose of this research is to know the illumination of the light collimator and X-Ray light field alignment collimator on the conventional X-Ray. The research was done in the laboratory of the Radiology Department Baiturrahmah University. The type of research used quantitative methods experimental by directly examining. Research using Lux Meter, Collimator Alignment Test Tool and Beam Alignment Test Tool, with Film Focus Distance (FFD) $100 \mathrm{~cm}$. The Result showed that to test the collimator illumination lamp is 124.75 lux and similarity test results to file collimation is a light diversion $\triangle X$ equal $1 \mathrm{~cm}$ and $\triangle Y$ equal $1,3 \mathrm{~cm}$ and deviation of 1.5 degrees. This value is still in the measurement tolerance range of NCRP (National Council on Radiation Protection and Measurements) is $\triangle X$ and $\triangle Y \leq 2 \%$ FFD and deviation $\leq 3^{\circ}$. Thus, the collimator conventional $X$ Ray at Laboratory of Radiology Baiturrahmah University has complied with standard KEMENKES No.1250/MENKES/SK/XII/200 about Manual Procedure Quality Assurance of Radiodiagnostic.
\end{abstract}

Keywords: X-ray Toshiba type E2739, illuminance test, X-ray collimation test. 


\section{PENDAHULUAN}

Kendali Mutu (Quality Control) didefinisikan sebagai bagian dari program Jaminan Mutu (Quality Assurance, QA) yang aktifitas programnya lebih terfokus pada teknik-teknik yang diperlukan bagi pengawasan (monitoring), perawatan dan penjagaan elemen-elemen teknis dari suatu sistem peralatan radiografi, dan imaging yang memengaruhi mutu gambar. Oleh karena itu kualitas kontrol adalah bagian dari program QA yang berhubungan dengan instrumentasi dan peralatan (Papp, 2006).

Salah satu kegiatan kendali mutu pada pesawat sinar-X adalah pengujian terhadap tabung kolimasi yang terdiri atas:

1. Uji iluminensi lampu kolimator, yang bertujuan untuk mengukur kuat cahaya lampu kolimator pada jarak $100 \mathrm{~cm}$ dengan ukuran lapangan $25 \mathrm{~cm} \times 25 \mathrm{~cm}$. Uji iluminensi ini dilakukan menggunakan Illuminance meter (IM) dengan satuan Lux meter. Penilaian dan evaluasi nilai IM dilakukan sebanyak empat kali pengukuran dengan hasil harus lebih dari 100 Lux pada jarak 1 meter.

2. Uji kesamaan berkas cahaya kolimasi, yang bertujuan untuk mengukur akurasi berkas lampu kolimasi terhadap berkas sinar-X pada jarak $100 \mathrm{~cm}$. Nilai dan hasil evaluasinya yang tampak pada hasil radiograf memperlihatkan berkas sinar-X berada tepat pada setiap sisi berkas cahaya kolimasi. Namun jika terjadi penyimpangan, maka hasil dan evaluasinya harus memenuhi persyaratan bahwa penyimpangan bidang cahaya kolimator dengan berkas sinar-X bagian horizontal $(\triangle X)$ maupun vertikal $(\Delta Y)$ tidak boleh melebihi $2 \%$ dari jarak fokus ke bidang film (FFD), serta total penyimpangan dari bidang horizontal dan vertikal $(\Delta X+\Delta Y)$ tidak boleh melebihi 3\% dari jarak fokus ke bidang film (FFD) (Bc Centre For Disease Control, 2004). Beam Allignment Test Tool merupakan sebuah silinder dengan bola baja di bagian tengah setiap dasarnya yang tidak dapat ditembus radiasi. Berdasarkan Begum dkk, (2011) terdapat tiga kondisi sebagai berikut; (1) jika gambar yang terdapat pada bola atas overlap dengan gambar yang terdapat pada bola bawah, maka penyimpangannya $\leq 0,5^{\circ}$; (2) sedangkan, jika gambar dari bola atas terdapat pada lingkaran dalam, maka penyimpangannya sebesar $1,5^{\circ}$; (3) dan apabila gambar dari bola atas terdapat pada lingkaran terluar, maka penyimpangannya sebesar $3^{\circ}$.

Laboratorium Jurusan DIII Radiologi Universitas Baiturrahmah memiliki satu unit pesawat sinar- $X$ konvensional. Pesawat sinar- $X$ tersebut digunakan untuk keperluan praktek mahasiswa. Berdasarkan observasi diperoleh informasi bahwa pemakaian pesawat sinar-X dari tanggal 4 Januari 2017 sampai 27 januari 2017 kurang lebih sebanyak 147 kali. Dalam sehari, pemakaian pesawat sinar-X sebanyak 14 kali sampai dengan 28 kali. Pengujian terhadap pesawat ini terakhir dilakukan pada tanggal 27 November 2014 dengan hasil masih dalam batas toleransi. Namun pengujian perlu dilakukan kembali secara rutin karena berdasarkan KEMENKES RI 1250 tahun 2009 frekuensi uji seharusnya dilakukan setiap satu bulan.

\section{METODE PENELITIAN}

Penelitian yang digunakan adalah penelitian kuantitatif experimental dengan langsung meneliti ke lapangan. Lokasi penelitian di Laboratorium Jurusan DIII Radiologi Universitas Baiturrahmah dengan pengambilan data dilakukan pada Juni 2017. Alat dan bahan penunjang yang digunakan pada penelitian ini adalah; pesawat sinar-X konvensional dengan spesifikasi tabung pesawat merk Toshiba model E7239 nomor seri 1K0071 sebagai objek uji, Lux meter untuk mengukur iluminensi berkas cahaya 
kolimator, Collimator Alignment Test Tool untuk menentukan akurasi pada kesamaan antara berkas sinar-X dengan berkas cahaya, Beam Alignment Test Tool untuk mengevaluasi ketepatan berkas sinar- $\mathrm{X}$ dengan pusat berkas cahaya, film sinar-X, kaset berukuran $24 \mathrm{~cm} \times 30 \mathrm{~cm}$, pita pengukur dan jangka sorong.

\subsection{Uji Iluminensi Lampu Kolimator}

Cara kerja uji iluminensi lampu kolimator seperti yang diperlihatkan pada Gambar.1 dengan langkah-langkah sebagai berikut:

1. Menempatkan lux meter $100 \mathrm{~cm}$ dari fokus tabung sinar-X.

2. Memastikan bahwa detektor paralel dengan aksis anoda dan katoda.

3. Mengurangi semua pencahayaan dalam ruangan hingga gelap.

4. Menyalakan berkas cahaya pada kolimator dengan luas kira-kira $25 \mathrm{~cm} \times 25 \mathrm{~cm}$.

5. Melakukan pengukuran pada cahaya latar dalam ruangan.

6. Melakukan pengukuran untuk masing-masing titik pada empat luas bagian.

7. Mencatat hasil pengukuran

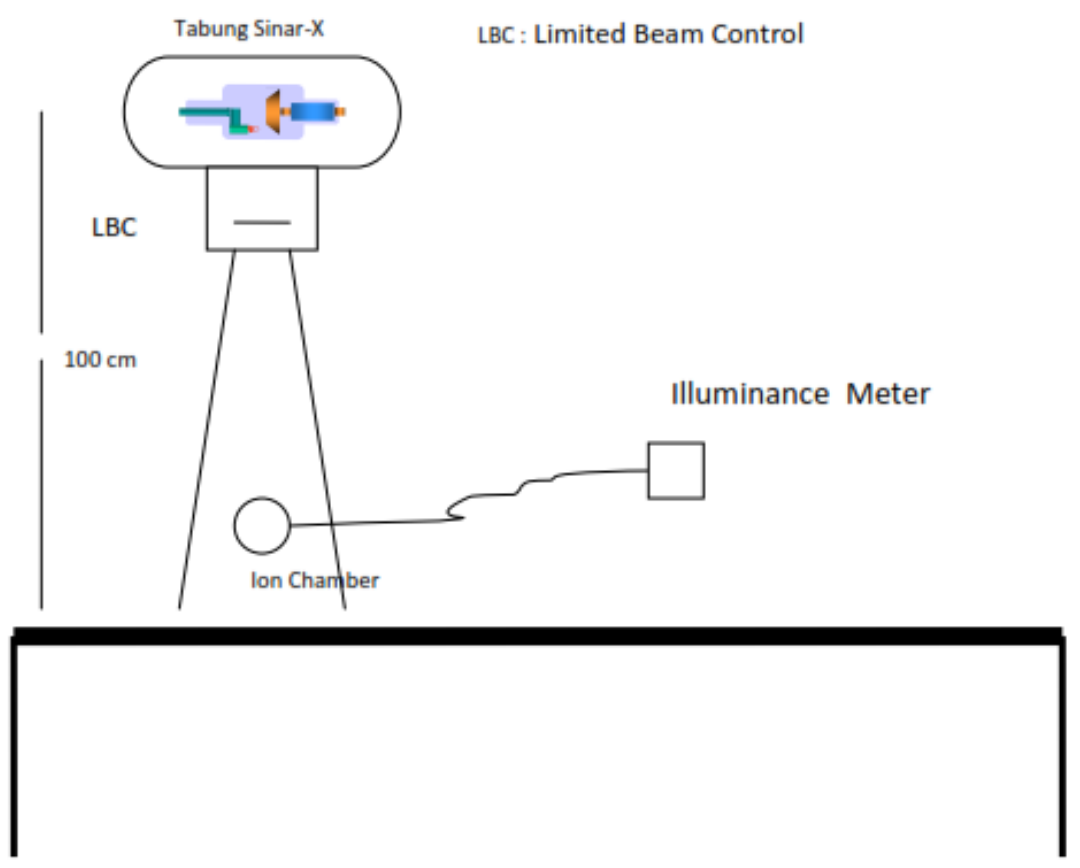

Gambar 1. Skema uji iluminensi lampu kolimator.

\subsection{Uji Kesamaan Berkas Cahaya Kolimator}

Pengujian kolimator pesawat digunakan seperangkat alat uji yaitu; (1) Collimator Alignment Test Tool untuk menentukan akurasi pada kesamaan antara berkas sinar-X dan berkas cahaya dan (2) Beam Alignment Test Tool untuk mengevaluasi ketepatan berkas sinar-X dengan pusat berkas cahaya. Faktor eksposi yang digunakan adalah $60 \mathrm{kV}, 75$ mAs, dengan menempatkan kaset di bawah lapangan penyinaran. Berdasarkan hasil pengujian kolimator diperoleh penyimpangan lapangan penyinaran.

Cara kerja uji kesamaan berkas cahaya kolimator seperti yang diperlihatkan pada Gambar. 2 dengan langkah-langkah sebagai berikut:

1. Meletakkan kaset ukuran $24 \mathrm{~cm} \times 30 \mathrm{~cm}$ pada permukaan yang datar.

2. Memastikan bahwa anoda dan katoda aksis adalah paralel ke kaset. 
3. Memusatkan sentrasi tabung sinar-X sehingga berada di tengah kaset dan mengatur jarak antara fokus dengan film (FFD) setinggi $100 \mathrm{~cm}$.

4. Menempatkan collimator test tool pada pertengahan kaset.

5. Mengatur cahaya kolimator tepat dalam area persegi panjang plat test tool.

6. Menempatkan beam alignment test tool pada pusat area pencahayaan.

7. Menghidupkan lampu kolimator dan mengatur luas lapangan cahaya sesuai dengan garis persegi panjang yang ada pada permukaan plat.

8. Melakukan eksposi radiografi agar diperoleh densitas optis pada film yang dapat diobservasi.

9. Memproses film di kamar gelap dan mengecek kesesuaian berkas cahaya/berkas sinar-X dan X-ray beam alignment.

10. Mengulangi eksposi untuk ukuran focal spot yang lain.

11. Mencatat perubahan skala lapangan radiasi $X_{2}$ dan $Y_{2}$ dan skala lapangan sinar kolimator $X_{l}, Y_{l}$ dalam lembar kerja dan membandingkan hasil pengukuran dengan standar NCRP ( $\leq 2 \%$ of FFD), dihitung dengan menggunakan persamaan (1).

$$
X_{1}+X_{2} \leq 2 \% \text { FFD dan } Y_{1}+Y_{2} \leq 2 \% \text { FFD }
$$

12. Untuk hasil pengukuran beam dilakukan dengan cara mengamati pergeseran gambar kedua bola baja dalam film, dan membandingkan dengan standar NCRP $\left(\leq 3^{\circ}\right)$.

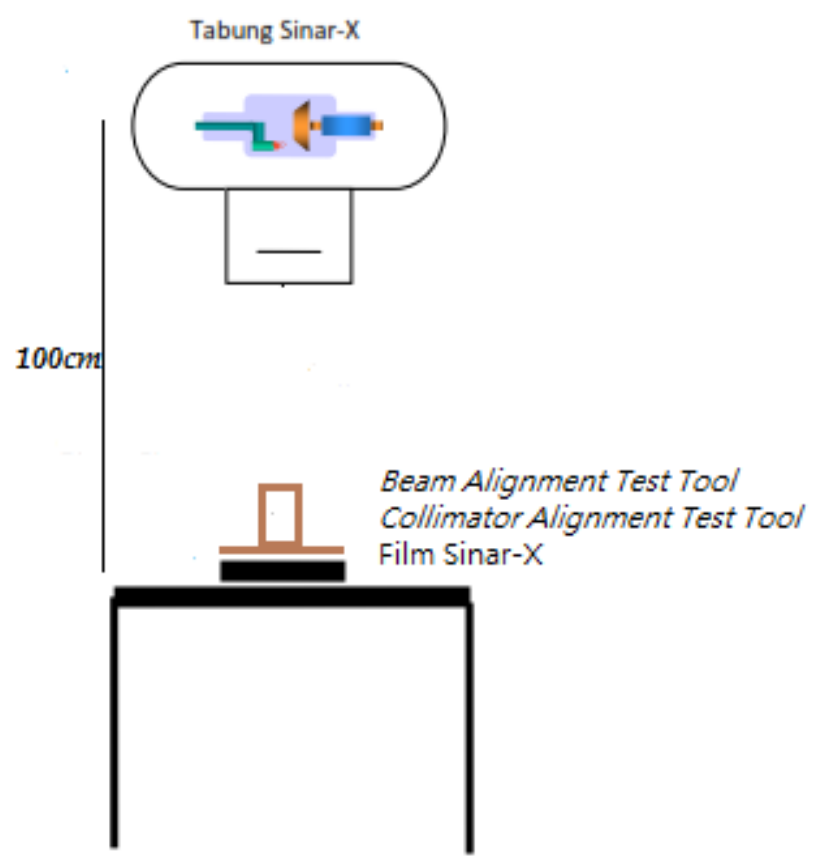

Gambar 2. Skema uji kesamaan berkas cahaya kolimator.

\section{HASIL DAN DISKUSI}

Berdasarkan penelitian yang telah dilakukan pada pesawat sinar-X merk Toshiba type E2739, didapatkan hasil pengujian iluminensi kolimator pada Tabel 1 dan hasil pengujian kesamaan berkas cahaya kolimasi pada Tabel 2 . 
Tabel 1. Hasil uji iluminensi lampu kolimator pada jarak $100 \mathrm{~cm}$ dan luas lapangan $25 \mathrm{~cm} \times 25 \mathrm{~cm}$

\begin{tabular}{cccccc}
\hline Titik & $\begin{array}{c}\text { Pengukuran } \\
\text { Ukur }\end{array}$ & $\begin{array}{c}\text { Rerata } \\
(\text { lux })\end{array}$ & $\begin{array}{c}\text { Cahaya } \\
\text { latar rerata } \\
(\text { lux })\end{array}$ & $\begin{array}{c}\text { Hasil ukur } \\
(\text { lux })\end{array}$ & Nilai lolos uji \\
\hline Area 1 & 256,00 & & & & \\
Area 2 & 247,00 & & & & \\
Area 3 & 258,00 & 256,75 & 132,00 & 124,75 & $\geq 1001$ ux \\
Area 4 & 266,00 & & & & \\
\hline
\end{tabular}

Tabel 2. Hasil uji akurasi berkas cahaya kolimasi dengan berkas sinar-X pada jarak $100 \mathrm{~cm}$

\begin{tabular}{cccccc}
\hline $\begin{array}{c}\text { Titik } \\
\text { ukur }\end{array}$ & $\begin{array}{c}\text { Lapangan } \\
\text { cahaya } \\
(\mathbf{c m})\end{array}$ & $\begin{array}{c}\text { Lapangan } \\
\text { sinar-X }\end{array}$ & $\begin{array}{c}\Delta \boldsymbol{\Delta} \text { dan } \Delta \boldsymbol{Y} \\
(\% \text { FFD })\end{array}$ & $\begin{array}{c}\Delta \boldsymbol{X}|+| \boldsymbol{\Delta Y} \mid \\
(\boldsymbol{\%} \text { FFD })\end{array}$ & Nilai lolos uji \\
\hline $\mathrm{X} 1$ & 9 & 8 & 1 & & $\Delta \mathrm{X}$ dan $\Delta \mathrm{Y} \leq 2 \% \mathrm{FFD}$ \\
$\mathrm{X} 2$ & 8,5 & 8,5 & & 2,3 & $|\Delta \mathrm{X}|+|\Delta \mathrm{Y}| \leq 3 \% \mathrm{FFD}$ \\
$\mathrm{Y} 1$ & 7 & 6,5 & 1,3 & & $\begin{array}{c}\text { Nilai lolos uji } \\
3^{\circ}\end{array}$ \\
\hline Y2 & 7,5 & 6,7 & $\begin{array}{c}\text { Hasil ukur } \\
1,5^{\circ}\end{array}$ \\
\hline
\end{tabular}

Keterangan: FFD (Focus Film Distance)

Hasil pengukuran pada pengujian iluminensi lampu kolimator menunjukkan bahwa pada setiap area nilainya berbeda meskipun dilakukan pada waktu yang bersamaan. Nilai cahaya lampu tertinggi terdapat pada area 4 yaitu 266,00 lux dan nilai terendah pada area 2 yaitu 247,00 lux. Nilai rata-rata dari keempat area adalah sebesar 256,75 lux, sedangkan nilai cahaya latar 132,00 lux, sehingga didapatkan hasil pengukuran adalah sebesar 124,75 lux. Berdasarkan hasil tersebut bahwa nilai cahaya lampu bisa diterima karena nilainya lebih tinggi dari 100 lux. Berdasarkan hasil uji lampu iluminensi, lampu kolimator mendekati nilai limit sehingga perlu segera dilakukan perbiakan. Dengan demikian, hasil secara keseluruhan nilai cahaya lampu dapat diterima karena melebihi 100 lux.

Hasil pengujian kesesuaian kolimasi menunjukkan bahwa $\Delta \mathrm{X}+\Delta \mathrm{Y}=2,3 \% \mathrm{FFD}$. Hasil tersebut menunjukkan bahwa kesesuaian kolimasi masih layak. Hal ini berdasarkan KEPMENKES No.1250/MENKES/SK/XII/2009 tentang Pedoman Kendali Mutu (Quality Assurance) Peralatan Radiodiagnostik yang menyatakan bahwa sebuah kolimator dikatakan masih layak jika $\Delta \mathrm{X}$ dan $\Delta \mathrm{Y} \leq 2 \%$ FFD dan $|\Delta \mathrm{X}|+|\Delta \mathrm{Y}| \leq 3 \%$ FFD, dengan $\Delta \mathrm{X}$ adalah jumlah dari $\mathrm{X} 1+\mathrm{X} 2$ dan $\Delta \mathrm{Y}$ adalah jumlah dari $\mathrm{Y} 1+\mathrm{Y} 2$.

Hasil pengujian ketepatan berkas pesawat sinar-X merk Toshiba type E2739 dengan pusat berkas cahaya menunjukkan bahwa terdapat pergeseran pusat dari lapangan penyinaran yang terlihat pada beam alignment tersebut. Dalan hal ini terjadi deviasi sebesar $1,5^{\circ}$ dari posisi normalnya. Walaupun demikian hasil pengukuran tersebut menunjukkan bahwa ketidaklurusan beam alignment masih dalam batas toleransi uji yang diperbolehkan menurut standar NCRP yaitu sebesar $3^{\circ}$.

Diskusi dari pembahasan di atas bahwa jika berkas cahaya kolimasi tidak sesuai dengan berkas radiasi yang dihasilkan maka akan berakibat pada objek hasil radiograf yang kita 
inginkan tidak akan tervisualisai dengan maksimal atau terpotongnya objek yang kita inginkan. Hal tersebut dapat mengakibatkan terjadinya pengulangan foto pada pasien, jika pengulangan foto dilakukan maka akan memberikan efek bertambahnya dosis radiasi yang akan diterima oleh pasien dan akan bertambah juga dosis radiasi yang diterima oleh petugas atau operator pada pesawat tersebut.

\section{KESIMPULAN}

Berdasarkan hasil pengujian tabung kolimator pesawat sinar-X merk Toshiba type E2739, dapat disimpulkan bahwa hasil uji iluminensi lampu kolimator adalah 124,75 lux, uji kesesuaian cahaya kolimasi dengan berkas sinar-X adalah $\Delta X+\Delta Y=2,3 \%$ FFD dan uji beam alignment adalah $1,5^{\circ}$. Semua nilai tersebut masih dalam batas toleransi yang diperbolehkan. Kolimator pesawat sinar-X merk Toshiba type E2739 di laboratorium jurusan DIII Radiologi Universitas Baiturrahmah pada tahun 2017 dinyatakan lolos uji dan masih layak untuk digunakan.

Sebaiknya pengujian terhadap pesawat sinar-X merk Toshiba type E2739 di laboratorium jurusan DIII Radiologi Universitas Baiturrahmah dapat secara rutin dilakukan sesuai dengan periode waktu uji. Disamping itu, apabila terjadi kerusakan akibat gempa bumi maka segera dilakukan perbaikan dan dilakukan uji kesesuaian terhadap pesawat tersebut, agar kinerja dari pesawat tetap terjaga dan selalu bisa dimanfaatkan untuk praktikum mahasiswa dengan baik.

\section{UCAPAN TERIMAKASIH}

Peneliti mengucapkan terimakasih kepada Jurusan DIII Radiologi Universitas Baiturrahmah yang telah banyak membantu dalam penelitian ini.

\section{DAFTAR PUSTAKA}

American Association of Physicists in Medicine Report No. 4. (1981). Basic quality control in diagnostik radiology. United States of America: Author.

Bc Centre for Disease Control. (2004). Diagnostic X-ray unit QC standards in British Colombia. Canada: Author.

Begum, M., Mollah, A. S., Zaman, M. A., \& Rahman, A. K. M. M. (2011). Quality control tests in some diagnostic X-ray units in Bangladesh, Bangladesh Journal of Medical Physics, 1(4), 58-66.

Keputusan MENKES RI No. 1250 Tahun 2009. (2009). Pedoman kendali mutu (quality control) peralatan radiodiagnostik (hal 8-11). Jakarta: Pengarang.

Kusumawati, D., Prasetio, D., Yuliati, H., \& Suyati, H. (2009). Urgensi compliance test pada radiodiagnostik. Prosiding Seminar Nasional Keselamatan, Kesehatan dan Lingkungan IV, Pusat Teknologi Keselamatan dan Metrologi Radiasi-BATAN, Jakarta, Indonesia.

Peraturan Kepala BAPETEN No. 9 Tahun 2011. (2011). Uji kesesuaian pesawat sinar-X radiologi diagnostik dan intervensional. Jakarta: Pengarang.

Susanti, Rika dkk. (2017). Uji kesesuaian pesawat Fluoroskopi Intervensional merk Philips Allura FC menggunakan detektor Unfors Raysafe X2 di Rumah Sakit Universitas Andalas. Jurnal Fisika Unand, 6 (3), 232-239.

Wibowo \& Gatot, M. (2014). Penerapan program uji kesesuaian pada peralatan sinar-X Direct Digital Radiography (DDR) di Laboratorium Radiografi dan Imejing Poltekes Kemenkes Semarang, Ejournal Poltekes Semarang, 10 (2), 792-800. 